\title{
Neurofeedback
}

\section{A non drug treatment of Attention Deficit/Hyperactivity Disorder}

\author{
B H N Yasmeen ${ }^{1}$
}

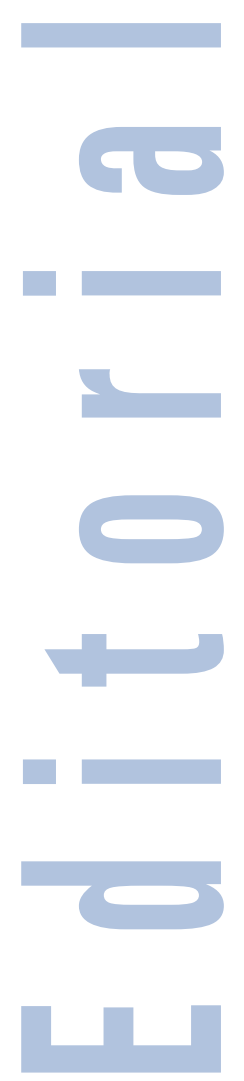

${ }^{1}$ Dr. B н Nazma Yasmeen MBBS, MCPS, MD (Paed) Editor

Northern International Medical College Journal

\section{Associate Professor Dept. of Paediatrics Northern International Medical College, Dhaka email :}

drnazmayasmeen @ yahoo.com

\begin{abstract}
Attention Deficit/Hyperactivity Disorder (ADHD) is characterized by persistent symptoms of inattention or inattention in combination with hyperactivity and impulsivity. It exists in all countries and cultures and its prevalence may be up to one in four of the child population. ${ }^{1}$ The severity of these symptoms and its enduring nature are known to impair a person's capacity to effectively function.
\end{abstract}

At the present time, ADHD is not curable; it is manageable. Because of rapid improvements in attention and reduced hyperactivity, many children with ADHD have been treated with drugsstimulants. ${ }^{2}$ However, improvements in social and academic skills following stimulant treatment have not been reported. ${ }^{3}$ In addition, concerns with the benefits and side effects of long-term stimulant treatment have also been noted. ${ }^{4}$

In the last few decades many clinical trials have found that a newer treatment modality, Neurofeedback (NF) also effectively treats the symptoms of ADHD. ${ }^{5}$

Neurofeedback - also known as EEG Biofeedback is an ADHD treatment procedure in which individuals learn to alter their typical EEG pattern to one that is consistent with a focused, attentive state. This is done by collecting EEG data from individuals as they focus on stimuli presented on a computer screen. Their ability to control the stimuli, for example, keeping the smile on a smiley face or keeping a video playing, is contingent on maintaining an EEG state consistent with focused attention. Neurofeedback proponents argue that this ability generalizes to real world situations and results in better attention during academic and related tasks.

Children with $A D H D$ have higher rates of EEG abnormalities compared to children without ADHD, such as higher theta wave rhythms (drowsiness), lower sensorimotor rhythms (movement control), and lower beta waves (attention and memory processes). ${ }^{6}$ Neurofeedback provides audio and visual interpretations of these brain waves, and children learn how to maintain the appropriate levels for functioning. The goal of the NF treatment was to enhance beta and depress theta activity. ${ }^{7}$

During a neurofeedback session, EEG sensors are situated on the scalp of the patient. Specific brain wave activity is then detected, amplified, and recorded. The information is instantaneously fed back to the therapist and client on a screen. The therapist informs the client what they are observing, and trains them on how to control the brain activity so that it reaches the desired range. With the help of a video game program, the child learns to maintain low activity of the delta waves and an increase in beta waves, or the game will not continue to play. With this, the child exercises the brain and increases his focus and attention. Ultimately with repeated practice sessions, (e.g 40 minute session 3 times per week over 10 weeks, i.e.30 sessions or 30 minutes/session provided over 20 weeks) trainees become more readily able to produce "healthier" brainwaves and alleviating their symptoms. Once learned and solidified in training, the ability to access these productive patterns of brain activity generalises to everyday life, with changes in most cases being permanent.

Anecdotal research shows neurofeedback may be a potentially useful intervention for a range of brain-related conditions. It has been used for $\mathrm{ADHD}_{1}{ }^{8}$ anxiety/depression, ${ }^{9}$ autism, ${ }^{10}$ epilepsy, ${ }^{11}$ headaches, ${ }^{12}$ Sleep problems, ${ }_{1}^{13}$ and other causes.

Many clinical trials have found that neurofeedback effectively treats the symptoms of ADHD. ${ }^{5}$ The effects of NF have been described as improved attention, decreased hyperactivity, and increased academic and social skills. ${ }^{1,8}$ Fuchs and Lubar suggested that introduce NF as a treatment option for children with ADHD whose parents favored a non-pharmacological treatment. ${ }^{14,15}$

Neurofeedback participants made more prompt and greater improvements in ADHD symptoms, which were sustained at the 6-month follow-up, than those in the control group. This finding 
suggests that neurofeedback is a promising attention training treatment for children with ADHD. In 1995 Alhambra, Fowler and Alhambra in a controlled study, comparing neurofeedback to other treatments for ADHD showed that after 30 sessions of neurofeedback, 16 of 24 patients taking medications were able to lower their dose or discontinue medications totally. No serious adverse side effects from neurofeedback have been reported. ${ }^{16}$

Monastra VJ, Monastra DM and George (2002) studied 100 children with $A D H D$ receiving Ritalin, parent counseling and academic support. 50 children also received neurofeedback. While all children improved on the Test of Variables of Attention (TOVA) and an Attention Deficit Evaluation Scale (ADDES) while taking Ritalin, only those who had NF sustained those improvements after discontinuing Ritalin. ${ }^{4}$ However, in some other studies have only found improvements in attention ${ }^{17}$ and two studies with large sample sizes did not find significant improvements in core ADHD symptoms. ${ }^{4,18}$

Therefore it is found that NF for ADHD has been controversial for many years, research support for this treatment is growing. In fact, in October, 2012 the American Academy of Pediatrics rated neurofeedback as a Level 1 "Best Support" Intervention for ADHD; this is the highest possible rating and at the same level as medication treatment and behavior therapy. ${ }^{19}$

Recently a few number of Paediatricians started practicing Neurofeedback therapy in the treatment of ADHD in our country. Hope in the near future we will get a result of our population in this regard.

\section{References}

1. Monastra VJ, Lynn S, Linden M, Lubar JF, Gruzelier J, LaVaque TJ: Electroencephalographic biofeedback in the treatment of attention-deficit/hyperactivity disorder. Appl Psychophysiol Biofeedback 2005, 30(2):95-114. PubMed Abstract । Publisher Full Text

2. Barbaresi W, Katusic $S$, Colligan R, Weaver A, Pankratz V, Mrazek D, Jacobsen S: How common is attention-deficit/hyperactivity disorder? Towards resolution of the controversy: results from a population-based study.ActaPaediatrSuppl 2004,93(445):5559. PubMed Abstract

3. Wagner KD: Management of treatment refractory attention-deficit/hyperactivity disorder in children and adolescents. Psychopharmacol Bull 2002, 36(1):130-142. PubMed Abstract
4. Monastra VJ, Monastra DM, George S: The effects of stimulant therapy, EEG biofeedback, and parenting style on the primary symptoms of attention-deficit/hyperactivity disorder. Appl Psychophysiol Biofeedback 2002, 27(4):231-249. PubMed Abstract । Publisher Full Text

5. Fox DJ, Tharp DF, Fox LC: Neurofeedback: an alternative and efficacious treatment for Attention Deficit Hyperactivity Disorder. Appl Psychophysiol Biofeedback 2005, 30(4):365-373. PubMed Abstract |

6. (at: http://www.helpforadd.com/2013/september.htm).

7. Othmer SF: Interhemispheric EEG training.J Neurotherapy 2005,9:8796.Publisher Full Text

8. Arns M, de Ridder S, Strehl U, Breteler M, Coenen A: Efficacy of neurofeedback treatment in ADHD: the effects on inattention, impulsivity and hyperactivity: a metaanalysis. Clin EEG Neurosci 2009, 40(3):180-189. PubMed Abstract | Publisher Full Text

9. Linden $D E$, Habes I, Johnston SJ, Linden S, Tatineni R, Subramanian L, Sorger B, Healy D, Goebel R. (2012). "Real-time self-regulation of emotion networks in patients with depression." PLOS ONE7 (6): e38115. doi:10.1371/journal.pone.0038115. PMID 22675513.

10. Coben R, Linden M, Myers TE. (2010). "Neurofeedback for autistic spectrum disorder: a review of the literature.".Applied Psychophysiology and Biofeedback35(1): 83-105. doi:10.1007/s10484-009-9117-y. PMID 19856096.

11. Tan G, Thornby J, Hammond DC, Strehl U, Canady B, Arnemann K, Kaiser DA. (2009). "Meta-analysis of EEG biofeedback in treating epilepsy.".Journal of Clinical EEG \& Neuroscience40 (3): 173-179. doi:10.1371/journal.pone.0038115. PMID 22675513.

12. Jeffrey A. Carmen PhD. (2005). "Passive Infrared Hemoencephalography: Four Years and 100 Migraines." Journal of Neurotherapy8 (3): 23-51. doi:10.1300/J184v08n03_03.

13. Cortoos A, De Valck E, Arns M, Breteler MH, Cluydts R. (2010). "An exploratory study on the effects of tele-neurofeedback and tele-biofeedback on objective and subjective sleep in patients with primary insomnia.".Applied Psychophysiology and Biofeedback35 (2): 125-134. doi:10.1007/s10484-009-9116-z. PMID 19826944.

14. Lubar JF, Lubar JO: Neurofeedback Assessment and Treatment for Attention Deficit /Hyperactivity DisordersIntroduction to Quantitative EEG and Neurofeedback. Academic Press, New York;1999:103-41.

15. Fuchs T, Birbaumer N, Lutzenberger W, Gruzelier JH, Kaiser J: Neurofeedback treatment for attention-deficit/hyperactivity disorder in children: a comparison with methylphenidate. ApplPsychophysiol Biofeedback2003, 28(1):1-12. PubMed Abstract | Publisher Full Text

16. Moriyama TS, Polanczyk G, Caye A, Banaschewski T, Brandeis D, Rohde LA (July 2012).Evidence-based information on the clinical use of neurofeedback for ADHD. Neurotherapeutics9(3): 588-98. doi:10.1007/s13311-012-0136-7. PMC 3441929. PMID 22930416.

17. Bakhshayesh AR, Hansch S, Wyschkon A, Rezai MJ, Esser G: Neurofeedback in ADHD: a single-blind randomized controlled trial.Eur Child Adolesc Psychiatry 2011.

18. Rossiter $T$ : The effectiveness of neurofeedback and stimulant drugs in treating AD/HD: part II. Replication. ApplPsychophysiol Biofeedback 2004, 29(4) : 233 - 243. Publisher Full Text

19. at:http://coe.csusb.edu/documents/CRPsychosocialInterventions.pdf . 